\title{
China and Africa: Can They Cross the Borders of System and Culture? - A Business Anthropology Research on an Unsuccessful Glass Factory Project Owned by a Sino-Botswana Joint Venture ${ }^{1}$
}

\author{
Wei $\mathrm{Xu}^{2}$ \\ Zhejiang Normal University
}

This paper is about the long term and in-depth fieldwork on a glass factory project executed by a Sino-Botswana joint venture. The background of bilateral relations between China and Botswana from diachronic perspectives is introduced, firstly. This provides the context for discussing the origin of the project. Then, the paper reveals the cooperative and conflictive aspects embedded in the construction of the factory from synchronic perspectives, through data obtained from participant observation. These include operation mode, Chinese company's adaption to Botswana local laws and regulations, the gaming between the partners, industrial diversification of Botswana, impacts of political struggle in Botswana on the project, etc. This paper further juxtaposes the discourse generated by the media with in-depth interviews with all parties involved in the projects to show the tremendous differences between these two distinct cultures, systems, and ideologies.

\section{INTRODUCTION}

Political, economic, and cultural cooperation and exchange between China and Africa have increased in recent years. At the same time, Sino-African relations, particularly in the areas of education, politics, and business, have received more attention globally. The issues raised during this process include China's investment and economic activities in Africa as well as the influences of these activities on the development of Africa and Chinese migration to Africa (Alden, 2007; Raine, 2009; Hofstedt,2009; Yoon and Chen,2009). According to incomplete statistics, at present, there are over one million Chinese people living on the continent. The activities of these Chinese people vary, ranging from construction to wholesale and retail of small commodities and manufacturing sectors. China's "going out" strategy is not only largely responsible for the growing interest of Chinese enterprises, but also for the increasing presence of Chinese people in Africa, a continent viewed with significant economic growth potential. They establish their future in a Chinese style in this strange land and experience glories and hardships. This paper focuses on some of the issues, including suspicions and doubts that lead to misunderstanding and conflicts between Chinese and Africans when the two peoples come together. As Sino-African relations further develop with time, we can observe the ways in which the differences, misunderstandings and disputes between Chinese and African actors have become more complicated. Behind making 
Sino-African relations more complicated are the Western powers' responses to China's growing economic strength and presence in Africa; these include the West's claim of China being a neocolonial power on the continent, neglecting its own as well as African countries' human rights abuses, and allowing the sale of poor-quality goods to Africa.

In Africa, public opinion seems to follow the West, condemning China for its exploitation of Africa and Africans and, in some countries, displaying signs of anti-Chinese sentiments. However, in this paper, I aim at showing that the relationship between African and Chinese actors on the ground are more complex than how it has been represented and discussed in the media. I argue that many rumors, suspicions, and misunderstandings have resulted from a lack of fieldwork and in-depth investigations. As such, this paper, which relies heavily on fieldwork in Botswana and engagement with actors involved in a project to construct a Sino-Botswana glass factory, discusses the living conditions of Chinese people in Africa and their activities. More broadly, it examines the process of cooperation between a group of Chinese actors and local people that is both complicated and confusing. Through interviews and analyses of local documents, this paper aims at revealing some of the sources of doubts, misunderstandings, and conflicts, including cultural differences between Chinese and Africans involved in a relatively large collaborative project.

As a sub-discipline of the Applied Anthropology, Business Anthropology is still an emerging inter-discipline marginalized in China. It mainly focuses on solving the practical problems in business by applying the theories and methodologies of anthropology. The research methodology applied is ethnography, the most common one in anthropology. However, its theoretical features are not distinct. At present, except "Business Anthropology" and "Introduction to Business Anthropology" (Tian and Zhou, 2012; Tian and Zhou, 2013), two works wrote jointly by Professor Tian Guang and Professor Zhou Daming, other theoretical works about this field can scarcely be found in China. Furthermore, almost all the research topics involved in the case studies are traditional ones such as ethnic groups, religions and family clan. The researches on the institutional management and culture of Chinese companies are seldom carried out, especially those exploring how Chinese companies cooperate with foreign companies and foreign culture during their internationalization (Chen and Guo,2015; Tian, 2010). As Professor Tian Guang said, "During the internationalization, the Chinese company is surely to meet the foreign culture and customs. Therefore, anthropologists specialized in Business Anthropology research are needed to provide 'cultural suggestions' for companies to successfully carry out their business activities, thus to help Chinese workers integrate their culture background with the 'local culture' of a foreign country and further to promote the long-lasting development of the company" (Tian, 2012). The case study in this paper is about an unsuccessful glass factory project owned by a Sino-Botswana joint venture. It discusses the culture differences and conflicts faced by both parties during the construction of this glass factory. From the cultural perspective such as different social systems and concepts, this study explores the root reasons behind the differences and conflicts.

The methodologies of anthropological field study and case study are applied in this paper. This study benefits largely from my spouse's role in the glass factory construction project; this connection has allowed me to visit the work site for long periods of time to observe how Chinese and Africans relate with one another and given me access to board and other staff members to interview. Through my personal connection, I have obtained objective and genuine information that is rarely available to researchers. During January 2012 to January 2013, I moved to and lived in Gaborone with my spouse, but I also took on a visiting scholar position at the University of Botswana. My relocation to the country gave me the opportunity to do research and collect first-hand information about the conditions in Botswana as well as to investigate the living conditions of the Chinese people who have migrated to the country. The collection of data included reports from the local media, namely popular newspapers, on the presence of Chinese people and the glass factory project itself. Nearly a hundred related news reports have been collected and analyzed. Through the study of the discourse in the popular media, and the function and influence of the glass factory on the local area have been analysed and then elaborated. 


\section{China and Botswana}

Since the establishment of diplomatic relations between China and Botswana in 1975, the two countries have continuously exchanged high-level visits, strengthened mutual political trust, supported each other's state sovereignty and territorial integrity, and shared much experience in exploring new ways of state governance and development. As far as the economic cooperation is concerned, bilateral trade between the two countries has increasingly expanded based on the principles of equality and mutual trust and mutual respect. Sino-Botswana trade has reached to 266 million US dollars. The investment of China in Botswana also achieved a leap growth. In particular, the direct investment in the non-financial sectors reached 402 million US dollars in 2016 (CMFA, 2018). The Botswana Central Bureau of Statistics data show that in the first quarter in 2012, the total value of bilateral trade between China and Botswana reached 101.3 million US dollars (ECCOEPRC, 2012). Besides economic cooperation, the two countries have very close cooperation in cultural field. In 2008, Shanghai Normal University established a Confucius Institute in Botswana. Since its establishment, two to three hundred local students have enrolled to study Chinese language and culture each year, and the number has continued to grow. On the other hand, 396 students from Botswana came to China for study in 2016, 632 professional and technical personnel had successfully completed their training in China. Since China sent its first medical team to Botswana in 1981, 12 teams with 327 members have been sent there in total. At present, there are 46 medical team members in Botswana (CMFA,2018).

The relatively long-term, steady relationship between the two countries has encouraged many Chinese people to invest and create new businesses in Botswana. It is estimated that there are more than 30,000 Chinese people working in Botswana. While some Chinese people are originally from Jiangxi and Hubei Provinces, Northeast China, and Shanghai, the majority, 60 to 70 percent, are from Fujian Province.

People from Fujian Province are primarily engaged in small commodity wholesale and retail businesses. Their businesses are spread across urban and rural areas; in the rural areas, the presence of Chinese businesses has made it more convenient for local people to consume daily needed goods. Besides the traders, there are also those Chinese who came to Botswana to assist China's construction projects in the 1980s. Among them, some foresaw the vast market and development opportunities in Botswana and chose to stay in the country to develop independently. After more than ten years' persistent hard work, they not only have settled well in Botswana, but have also encouraged many relatives and friends to come to the country to pursue new opportunities. Other Chinese people now in Botswana have come from neighboring countries like South Africa and Zimbabwe; they are also attracted here by the stable social environment and China's continual economic interests in Botswana.

It is estimated that the Chinese companies in Botswana have created over 20,000 employment opportunities and contributed a lot to Botswana's construction and development. However, local people view the Chinese people as mysterious and separated from the local society because of the linguistic and cultural differences among the both. Extant stereotypes are gradually changing with time. Younger Chinese who are knowledgeable of technology, proficient in English, and experienced with management are leading the way towards dismantling some of the misunderstandings about Chinese people among the locals. They are cooperating and communicating directly with local governments as well as developing friendships with many local people. Some Chinese companies pay high attention to their social responsibility. Every year, they give donations to local charity organizations and offer scholarships to local students with outstanding academic achievement to study in China.

Generally, living condition of Chinese people in Botswana is better than that in most other African countries. Botswana is universally acknowledged as a country with least corruption and a relatively lower crime rate. It enjoys a stable political environment and constant development of economy, which has provided a favorable living and developing environment for the Chinese. However, with the revision of related policies in Botswana, the Chinese have started to come across many difficulties and problems. According to some Chinese businessmen, the business operation now is getting increasingly harder, which is largely affected by the local policies towards the Chinese. In comparison, the former President 
Fsetus Mogae held a friendlier attitude towards China than the current President Ian Khama. This change in leadership, with the leader having a less positive attitude towards his Chinese partner, has been one of the key factors in changing the opportunities that are available to the Chinese who are doing business or investing in Botswana. It is without doubt that changes such as this, which are influential on policies, would have an impact on whether the Chinese businessmen remain or leave Botswana in the near future. I shall further discuss this transformation below.

\section{Background of the Sino-Botswana Glass Factory Project}

For a long time, the diamond industry and cattle farming have been the two major industries in Botswana's economy. Although Botswana has a wealth of mineral resources, the shortage of professionals and modern equipment makes it extremely difficult to develop new manufacturing. As a result, the daily living and industrial products still rely on imports. Therefore, it has become the major goal for Botswana to develop a diversified economy. This goal has become more urgent since the outbreak of the world financial crisis in 2007. This crisis dramatically reduced the global demand for diamond, severely damaging Botswana's economy -- half of the country's financial income and two-thirds of its foreign exchange income relied heavily on the diamond industry. Against these backdrops, the manufacturing of glass, which entails silica sand, coal, sodium carbonate, and many other raw materials, has gained importance to the Botswana government. The government has made great efforts to attract foreign investment in glass manufacturing. The former president, Festus Mogae, vigorously promoted a Sino-Botswana glass factory project when he went to China for the Beijing Summit and Third Ministerial Conference of the Forum on China-Africa Cooperation in November 2006.

According to Tomas, a board member of the glass factory, "As early as 2004, the board had intended to build a glass factory in South Africa. We have done many feasibility researches and found that South Africa has a wide market. This country has a population of forty to fifty million people. But for a long time it only has one glass factory, namely PG Glass, which supplies glass among the 200 million people in 14 countries in the whole southern Africa region and enjoys the generous profit alone. In 2006, during the period when Botswana President Fsetus Mogae visited Beijing, he graciously invited our board members to meet him in Beijing after learning our plan through the Botswana ambassador in China. President Mogae expressed his eager wish that we could build the glass factory in Botswana. However, in fact, Botswana is not an ideal place. The small population, the inland geographical location and no coastline, all of these mean an increase of production and sales cost. But President Mogae was very persistent. He said that to build a glass factory in Botswana had long been his dream for many years and Botswana had all the raw materials needed for manufacturing glass. If we were willing to build our glass factory in Botswana, he would give support and cooperation in all aspects. The sincerity of the president touched our board members and at last we decided to build the glass factory in Botswana."

When the Beijing Summit concluded, President Mogae sent his Finance Minister at that time to investigate the project while he traveled with the board members of the glass factory to Shanghai to discuss the terms of their contract. The project of construction of glass factory was to be a joint venture of Botswana Development Corporation Limited (BDC) and Shanghai Fengyue Glass Company Limited (FYG). Since Botswana had no experience in constructing a glass factory or available human resources, President Mogae insisted that FYG be the larger shareholder of the project to provide technological support on design, civil engineering, installation, and production. BDC would simply provide financial support for the project. In this manner, the Sino-Botswana joint venture was agreed upon.

By mid-2007, the two parties signed a shareholders' agreement and the formal EPC (the Engineering, Procurement and Construction services) contract agreement in the mid-2008. FYG is both the bigger shareholder and EPC contractor. Normally speaking, the project should have started immediately once the EPC contract was signed. While the entire budget for the project was confirmed and everything was ready to begin, the Botswana government's fund and the BDC's credit were not ready until the beginning of 2010 . 
The latter was mainly due to the outbreak of global financial crisis from 2008 to 2010 . The financial crisis greatly crippled Botswana's economic structure that depended heavily on the export of diamond. During this period, FYG also suffered great economic losses: on the one hand, it suffered from the devaluation of the Pula to US dollars and the increased value of the Chinese yuan to US dollars; and, on the other hand, FYG had to face higher costs of raw materials, physical distribution, and labor recourse. These damages are important reasons for the funding shortage in the later stage of the construction project.

While the sluggish economic environment in Botswana affected the construction process of the glass factory, the change of political environment also affected the factory's fate. In April, 2008, President Mogae stepped down and the new President Khama came into power immediately. Unlike the former president, President Ian Khama did not show such a strong passion for the glass factory project. Unfortunately, the former Minister of the Ministry of Finance, who was once appointed by the former president to vigorously promote this project, died of cancer in 2011, which also had negative influence on the construction of this project. The departure of the two most important figures that initiated and supported the glass factory project in Botswana led the fate of the project to an uncertain condition.

After three years' preparation and waiting, the construction of the glass factory finally started in Palapye, an emerging industrial town in southeast Botswana, in July 2010. Palapye was chosen for two reasons: first, it is a strategic place, and second, it is the hometown of former President Mogae. Palapye is not only where the only coal colliery is located, but it also has the largest power station and soda ash manufacturer. This meant that the place could provide ample electricity and raw materials for glass manufacturing. The glass factory was supposed to have been completed by the end of 2011 and put into production. It was supposed to provide more than 400 employment opportunities for Botswana and produce 450 tons of float glass each day. But, in fact, the construction was forced to suspend in the end of 2011 because of funding shortage, and the unpreparedness of water, electricity and other supporting resources. The suspension brought great repercussions in Botswana and rumors were afloat. Some said that funds were corrupted by BDC, and others said that the Chinese people are liars. How did this shift happen? This paper will go in depth to discuss and analyze the cooperation and difference between the two parties during the construction of the glass factory.

\section{Cooperation and Difference during the Construction of the Glass Factory}

Although both China and Botswana are developing countries, they differ greatly in political and cultural systems. Therefore, it should be unsurprising that differences and disagreements would emerge during the cooperation process. A lack of communication between Africans and Chinese who choose to cooperate on a project further contributes to misunderstandings and distrust that could negatively affect the project. Here, I shall discuss several problems that have emerged in the glass factory project as a result of political and cultural differences and lack of proper communication between the two shareholders of the project.

\section{Difference in Operation and Management between FYG and BDC}

Registered in the British Virgin Island in 2007, FYG is an offshore company with its office headquarters in Shanghai. All the board members are Chinese and have ten to twenty years' experience in setting up factories and doing business in Africa. According to the contracts, FYG is both the major shareholder and EPC contractor. It is fully responsible for the design, construction and management of the whole glass factory. When the contract was signed in 2007, FYG immediately began recruiting skilled and experienced engineers, technicians and management professionals in the glass industry in China. In accordance with existing norms and standards in China, it completed the engineering design, manufacturing of equipment and materials and a full set of export through the advanced technology of Luoyang float glass. FYG is also a typical Chinese private company with all the major features and problems of a private company: its several top directors have absolute powers; it does not have a 
management system and culture of a western enterprise; its management and operation is run more by individual personalities than by law. However, high-level directors are not almighty. They do not have a good understanding of some business rules or project issues or the local legal systems, when they make decisions, thus often leading the company into unnecessary problems and financial losses.

BDC is a state-owned company founded in 1970. It is devoted to the state commercial and industrial development and mainly provides financial support and supervision for projects. BDC is led by a board, whose members are appointed and dismissed by the Minister of Finance and Development Planning. The company is managed by the Managing Director with the assistance of two General Managers. BDC is a state-owned investment company that invests in many projects playing the role of a fund raising institution and a partner. The glass factory is one of those invested projects. However, since Botswana is almost inexperienced in the manufacturing sector and BDC has no technological and managerial personnel in glass industry, it is impossible for BDC to supervise and cooperate effectively. As a result, many supporting facilities like water and electricity as well as visa service could not meet the demand. So, the project process was delayed. In fact, BDC does not have technology basis and management capacity in many mass projects at all.

As outlined here, it should be obvious that FYG is a private company that is organized and driven by profit-making while BDC is a state-owned investment entity that is set up to serve the country's aim, especially to develop a diversified economy. Both are fundamentally different in operation and management styles, which have made gaming during the cooperation process possible.

\section{Gaming between the Two Cooperation Parties}

The total investment capital of the glass factory project is 500 million Pula, consisting of the injection of equity capital from the two cooperating parties and a loan from the Botswana Government. As the Botswana government is the main funding source, the BDC not only has the responsibility to monitor the quality of the project and its progress, but also to regulate FYG's use of funds. However, as mentioned before, since BDC has neither experience nor personnel in the glass industry, it is unable to have an effective regulation. Therefore, BDC commissioned G4, a local structural engineering consultant, to regulate the glass factory project. Here began the gaming between the two parties. According to Simon's statements, the FYG Executive Director noted that G4 was also inexperienced in the glass industry. It not only failed to effectively monitor the project, but was also exploited by the commercial and political struggle that had emerged. As a result, G4 attracted a lot of negative attention to the glass factory project. In particular, the project was implicated in a corruption scandal. As the local newspaper reported, in May 2011, G4 made a copy of the audit report, noting that BDC paid an extra of 100 million Pula to FYG and accused the glass factory project of its slower process than expected. G4 also claimed that corruption might exist inside BDC regarding this project (Mogapi , 2011). Soon, all the major media reported the glass factory project. Clamorous rumors and suspicions put $\mathrm{BDC}$ and the glass factory project on the forefront (Balise, 2011). The DCEC (Directorate on Corruption and Economic Crime), the anti-corruption agency of Botswana, investigated into BDC (Balise, 2011) and many related members were accused of corruption and were dismissed (Ramadubu, 2011). The Ministry of Finance and Development Planning of Botswana reappointed the members of BDC Board of Directors and said that "The new board would be required to resolve any outstanding issues threatening the successful completion and implementation of the Float Glass Manufacturing project under construction in Palapye" (Baleseng, 2011). BDC no longer employed G4. Instead, it hired a consultant firm with rich experience in the glass industry from the United Kingdom to evaluate and supervise the glass factory project. According to Simon, after two days' visit, experts from the United Kingdom all positively affirmed the engineering quality and design art.

$\mathrm{BDC}$ and FYG were both collaborators and competitors in pursuing their own interests. Economic interest was the main goal of the competition. In order to supervise the project, BDC firstly employed G4 and later hired the consulting firm from the United Kingdom. But, unexpectedly, G4 put BDC into the 
corruption scandal. It was more than simply for economic gains. Both the little-known economic war and the necessity of political struggle are important hidden causes.

\section{Influence of Political Struggle on the Glass Factory Project}

From May 2011 to the end of that year, the news about BDC and the glass factory project dominated Botswana's major newspapers' headlines. It was reported that FYG would be sold by auction because it fell behind with the material funding and could not submit the performance bond (Morula, 2011). This report made many people believe that this project would fail. The Chinese could not understand why such an industrial project would draw so much public attention mere based on rumors. Strangely enough, no local media conducted investigation on FYG to verify whether the reports were true or not. Instead, it was BDC, a state-owned company and the Chinese cooperation partner, that became the spotlight. After all, the political struggle was the root cause.

Since 1966 when Botswana declared its independence from the United Kingdom, the new national government implemented a Multiparty Parliamentary Democracy and Presidential Cabinet. The Botswana Democratic Party (BDP) has always been the ruling party and the major oppositional parties include the Botswana National Front (BNF) and the Botswana Congress Party (BCP). Since independence, Botswana has remained its political stability, realized rapid economic development and improved people's living standards. Thus, Botswana was hailed as a model of democracy and development in Africa. However, in recent years, the support rate of Botswana Democratic Party has begun to fall especially due to the fierce competitions within BDP. In 2010, some politicians who held different political views from Present Khama split from BDP and formed a new party with some members of the Parliament. This party was called Botswana Movement for Democracy (BMD), the first political party that split from the ruling party in history. BMD was known as being committed to the protection and development of the power of the people, the removal of the current undemocratic phenomenon in government, and the fight against the dictatorship.

The year 2013 was the election year in Botswana. As a new political party, BMD was seeking every opportunity to expand its influence to gain seats in the Parliament, and compete with BDP for power. The glass factory project would inevitably be a tool of political struggle in the country with the media paying close attention to it. On December 1, 2011, BMD sent a report to BDP titled "BOTSWANA MOVEMENT FOR DEMOCRACY MAKES HISTORY IN BOTSWANA----Botswana Development Corporation (Fengyue Glass Project) Motion." Its main intention was to promote the establishment of a Special Selected Committee in the Parliament to investigate BDC and the glass factory project (Modise, 2011). At the same time, the reports about BDC corruption and the tricks in the glass factory project reached a climax. Some media reports were even just like the Hollywood soap opera (Kavahematui, 2011). However, there were little-known political purposes and struggles hidden behind these reports.

The internal political struggle in Botswana cannot be known by the author, but the influence of political struggle on the glass factory project was obvious. First, the project in Botswana was well known to all and most of the comments were negative. BDC was trapped into scandal swirls and had no time to care about this project. Second, the cooperation between the project and the local departments as well as the suppliers was getting increasingly difficult since the project was discredited by those negative reports. Lastly, many people lost their confidence in the glass factory and even the internal employees became anxious. All of these facts greatly influenced and further delayed the construction process of the glass factory. Eventually, the project was suspended at the end of 2011 because of funding shortage.

\section{Cultural difference between China and Botswana from the Anthropological Perspectives}

After the description of the project background and differences in the cooperation, this paper tries to make a deeper analysis from the culture and anthropology perspectives. All the human activities are deep rooted in culture. What is culture? As British anthropologist Tylor put it in 1871, "Culture or civilization, from a broad ethnology perspective, is a compound as a whole, including knowledge, belief, art, morality, 
law, custom and all the other abilities and habits acquired by social members" (Tylor,1871). Obviously, this definition defines culture as a general term of all the human creations during the process of social development, including material and technology, social system and human creations. In the transnational glass factory, the employees came from different countries and had different cultural backgrounds, and the cultures are deeply rooted in real life. This paper will focus on social system and concept of spirit to analyze the cultural difference between China and Botswana. A transnational enterprise can succeed only by understanding and recognizing cultural differences, and establishing a friendly work atmosphere in the enterprise. The "cultural differences" not only can be used to question the managers' assumptions of the "right" ways of doing things, but also can promote them to study the new methods to solve the problems (Tian, 2013).

\section{When Socialism with Chinese Characteristics Meets Democracy with Botswana's Characteristics}

The establishment of a social system is shaped by its special history, customs and values. China and Botswana have totally different social systems, but both have come out of poverty and become relatively wealthy countries during the last forty years of rapid development. Botswana's democracy is praised as a model among African countries. With a system of socialism with Chinese characteristics, China's GDP has grown at a rate of 10 percent per year and developed into the world's second largest economy following America in 2008. But, why do these two countries encounter so many difficulties and differences on the joint venture of the glass factory project?

The theory of "socialism with Chinese characteristics" was put forward by Deng Xiaoping, the chief designer of China's reform and opening-up policy. It stresses that "poverty is not socialism", "making our economic development as our central task, liberating and developing productive forces", "black or white: good cat is mouse-catching", and "learning as we go". Even the capitalistic system can be referred to, learned from and introduced in as long as it is conducive to the improvement of the productive force, national strength, and people's living standard. China's reform started with these policies. On the premise of state-controlled economic lifeline, China has undertaken radical changes in the last thirty years with the development of non-state-owned economy and the introduction of market economy system. But, China's political system is still characterized by socialism. It adheres to the constitution that has inscribed the Communist Party as the only ruling party in the country and adheres to the system of multi-party cooperation and political consultation under the leadership of the Communist Party of China. Under this situation, economic interests become the ultimate goal. The improvement of all the aspects of social system and rules is overlooked. This leads to the lack of power constraints and capital supervision. As a result, the Chinese people have developed a flexible ideology and practices to achieve the above mentioned objectives, which include fair and foul means in the pursuit of economic interests.

The business activities of Chinese people in Botswana indeed reflect Chinese characteristics, namely being unruly and flexible, taking the pursuit of interests as the sole objective and so on. All of these features lead to the local people's distrust for the Chinese. They take it for granted that there are tricks in whatever projects with Chinese's participation, so are their opinions and attitudes towards the glass factory project.

On the African continent, democratic systems have failed in many countries. People live in extreme poverty. Under this condition, the democracy in Botswana is particularly valuable and successful. According to the democracy index rankings of Economist Intelligence Unit in 2011, Botswana ranked 33rd with a score of 7.63, ranking the third among the African countries (EIU, 2011). The per capita income in Botswana has always ranked the top among African countries, and the World Bank has already added Botswana into the "high and mid-income countries" list. Since 1998, Botswana has been chosen as the country with the least corruption in Africa by "Transparency International". According to its latest statistics in 2011, Corruption Perceptions Index of Botswana ranked 32nd in the world, still ranking 1st in Africa (China ranked the 75th in the world). Why is it that Botswana can achieve such outstanding success? One of the factors is the country's social system. Botswana has developed and implemented a 
constitution which combines modern and traditional civilizations and is in line with national situations. The constitution provides for the implementation of Multiparty Parliamentary Democracy and Presidential Cabinet. Meanwhile, it establishes the Council of Chiefs, whereby the status and powers of chiefs are retained at the grassroots and disparate clans are integrated to create stability and unity. In tradition, the chieftain system in Botswana heavily emphasizes democracy. When tribal disputes occur in the significant events, the chiefs hold tribal meetings where everyone is involved in the discussions and decision-makings. It can be referred to as a deliberative democracy. Until today, this tradition still remains in the village. However, this kind of deliberative democracy also has its negative aspect. Since whoever can speak in the decision-making, the power is too decentralized to concentrate and make quick decisions. This situation also occurs in the practical work of various government departments. In the Sino-Botswana glass factory project, Botswana could not keep up with the construction pace of the Chinese party. It could not provide supporting services such as water or electricity in a timely manner, resulting in delays of the project. In short, although Botswana has a complete and sound system, it often demonstrates a lack of execution and low efficiency subject to the low educational levels of the nation and weak ability to adapt to the industrial society.

\section{When "Time is Money" Meets "There Is No Hurry in Botswana"}

Anthropologists frequently discuss different socio-cognitive attitudes towards time. Time is often viewed as a social construct rather than a kind of natural existence. As Jack Goody (1991) says, "Although all societies have some system of time reckoning, some idea of sequence and duration, the mode of reckoning clearly varies with the political organization." Since China and Botswana have totally different natural and social environments, the modes of time reckoning in these two countries inevitably vary from each other.

Owing to a large population of 1.3 billion people, China has very limited per capita resources in spite of being an industrial power. In order to achieve the goals of industrialization and modernization, the Chinese people work overtime from dawn to dust as if running against time. As a result, in Chinese culture, time has come to be equated with money. This is the attitude towards time in all the industrial societies. However, African people's concept of time is still based on the requirements of the traditional society. As such, "African time" is taken to mean that things happen when they happened, not when your timetable said that they should or would happen.

There is a saying in Africa, "Africans do not wait for time, rather, time waits for Africans." In Botswana, there is no other pillar industry project except for the diamond industry. Besides, it only has a small population of 2 million people who live comfortably with no threats from natural disasters, enjoying high welfare, free education and free medical care. People here always say that "There is no hurry in Botswana".

When China and Botswana cooperate to build the glass factory, there are a lot of conflicts on the attitudes towards time between the two parties. To the Chinese, time is money. But the Botswana are often unpunctual. Funding is delayed; supporting services cannot be kept up with; the appointments are always delayed or breached. All of these are closely related to the local people's concept of time. The Chinese people often complain that a similar glass factory project could be completed within one year in China, but it is still under construction after three years in Botswana. The loss of funding and rising costs during this period is immeasurable, but it seems that the Botswana people do not care, nor do they understand the importance of efficiency to industrial development. 


\section{CONCLUSION}

Although the construction was suspended at the end of 2011 because of funding shortage, the two parties renewed the agreement at the beginning of 2012 for additional funding. The Botswana government does not want to give up this project because it is vitally important for developing a diversified economy and changing the economic structure which merely depends on exporting diamond. President Khama promises to the nation that the glass factory project will go ahead as planned and the government will guarantee its successful completion ( Sefhako, 2012). His promise helped to stop the media hype that has lasted for more than half of a year. Also, the Chinese seem to be relieved and see signs of hope for the project. Although both the Chinese people and the Botswana people are continuously adjusting themselves to bridge the gap between them - the Chinese, in particular, are trying their best to learn and meet rules and regulations in Botswana, the differences still exist between the two parties. Therefore, people cannot help wondering: can the glass factory be completed and put into production? In fact, this project was once again suspended at the middle of 2012 for lacking funds. The salaries of Chinese workers were defaulted for a long time. The project was suspended. A large collection of equipment and materials was left unused. All the Chinese workers withdrew, leaving the whole company in dead silence. The local media also stopped advocating this project. For the coming two years, the glass company started to clear the procedures, but the process was quite slow since Botswana wanted to find other investors to take over this company. According to the report on February 24, 2016 in "Overseas Chinese in Africa Weekly", a Chinese newspaper in Botswana, "The Sino-Botswana glass factory project that has cost over 500 million pula will be sold by auction this week. All the efforts for this project will be gone with the wind by then" (Piet, 2016). This announced that the nine-year-old Sino-Botswana glass factory which has been prepared for three years, constructed for three years and suspended for three years was a complete failure.

In fact, what has been described about the glass factory project in this paper is only the tip of the iceberg. The project has gone through so many setbacks and tests since the signing of the contract. Furthermore, one paper is far from enough to explicitly demonstrate the complexity of the problems that the two parties have encountered. Therefore, it does not mean much to overemphasize about the result of the project. What really matters is the awareness of differences the two parties face during the cooperation process. What's more, the key to the success of such a cross- boundary, cross-cultural and cross-social economic cooperative project is to find the mutual rules and implement them firmly. But the premise is to transcend the communicative barriers caused by language.

This paper explicitly explored a failed investment of Chinese company in Africa. The purpose is to show that Chinese companies should not be overconfident and overoptimistic in the backdrop of "Going Out" strategy and "One Belt and One Road" initiatives. It should also be realized that money can't solve all the problems. After experiencing so many setbacks and failures overseas, Chinese companies need to face the conflicts of different countries in institutions and cultures. These conflicts show that China's investment in Africa should be based on mutual benefit and trust and find the balance of bilateral interest, rather than be based on individual interests. The Chinese should also not just work hard blindly. It is more important for them to learn the local rules and policies, culture and customs, pay attention to the cultural differences and reach a balance between the two cultures. Only through a balance of interest and cultural difference can the two parties eliminate the misunderstandings and conflicts to achieve common goals. 


\section{ENDNOTES}

1. This research was funded by the National Social Science Youth project 2014; its name was " Research on the Change of Racial and Ethnic Relations in New South Africa”, project number: 14CSH007. This study was also supported by the project of the Zhejiang Collaborative Innovation Center 2011 "Institute of African Studies Zhejiang Normal University and China-Africa Cooperation Collaborative Innovation Center, project number: 16FZZX05W.

2. $\mathrm{Xu} \mathrm{Wei,} \mathrm{PhD} \mathrm{in} \mathrm{Anthropology} \mathrm{is} \mathrm{an} \mathrm{associate} \mathrm{professor} \mathrm{at} \mathrm{the} \mathrm{Institute} \mathrm{of} \mathrm{African} \mathrm{Studies,} \mathrm{Zhejiang} \mathrm{Normal}$ University, China. Her research areas include Race and Ethnic relations in Southern Africa, Chinese in Africa, and African Studies in Anthropology etc.

\section{REFERENCES}

Alden, Chris. 2007. China in Africa, London: Zed Books.

Raine, Sarah. 2009. China's African Challenges, London: IISS/Routledge.

Hofstedt, Todd A. 2009. "China in Africa: An African Response.” Naval War College Review, 62(3): pp.79-100.

Yoon Jung, Park and Chen Anna Ying. 2009. "Recent Chinese Migrations in Small Towns of Post-apartheid South Africa." Revue Europeene des Migrations Internationals(REMI), 25(1): pp. 25-44.

Yoon Jung Park. 2009. "Recent Chinese Migrations to South Africa: New Intersections of Race, Class \& Ethnicity." In Representation, Expression and Identity. Interdisciplinary Perspectives, edited by Tina Rahimy, 153-168.Oxford: Inter-Disciplinary Press.

Baleseng, Batlotleng. 2011. "Minister Explains Appointment of New Board.” Daily News, Tuesday November 22, No 220: p. 2.

Balise, Joseph. 2011. "BDC Glass Project Raises More Questions Than Answers." Sundaystandard News, June 26- July 2.

Dikarabo Ramadubu. 2011. "How the Chinese Trickled BDC." Botswana Guardian, November 11.

Balise, Joseph. 2011. "DCEC Pounces on BDC Amid Alleged Corruption Reports." Sundaystandard News, October2-8.

Chen, G., \&Guo, R. 2015. "The Transnational Operation of Business Anthropology: Based on the Chinese Enterprise in Southeast Asia." The Journal of Beifang University of Nationalities, No.3.

Chinese Ministry of Foreign Affairs. 2018. "Bilateral Relations Between China and Botswana." Accessed June 24, 2018. http://www.fmprc.gov.cn/chn//gxh/cgb/zcgmzysx/fz/1206_4/1206x1/ t6498.htm.

Economic and Commercial Counsellor's Office of the Embassy of China in the Republic of Botswana. 2012. "The First Quarter of 2012 Witnessed Over 100 Million US Dollars of Sino-Botswana Bilateral Trade Volume.” Accessed June 26, 2018. http://bw.mofcom.gov.cn/article/jmxw/201206/ 20120608197847. shtml.

Economist Intelligence Unit. 2011. “The Democracy Index 2011: Democracy Under Stress.” Accessed December14, 2018. http://www.eiu.com//public/topical_report.aspx?campaignid=Democracy Index2011.

Goody, Jack. 1991. “Time: Social Organization.” International Encyclopedia of Social Sciences, Vol. $16: 31$.

Kavahematui, Justice. 2011. "Danger Lurks for Motlhale's BDC Motion.” The Midweek Sun, Wednesday December 7.

Modise, Oliver. 2011. "Parliament Investigates BDC." Sundaystandard, December 4-10.

Oarabile, Mosikare. 2011. "Parliament to Probe BDC." The Botswana Gazette, Wednesday 07-13 December. 
Mogapi, Spencer. 2011. "Corruption Mars BDC Multi-million Pula Project.” Sundaystandard News, May $22-28$.

Morula, Morula. 2011. "Embattled Shanghai Fengyue Glass Company Auctioned.” Sundaystandard, November 27-3 December.

Piet, Bame. 2016. "Fengyue Glass Project to Be Auctioned This Week." Mmegi, Feb 16.

Ramadubu, Dikarabo. 2011. "BDC Rots From the Head / Inside BDC's Shambles." Botswana Guardian, November 4.

Sefhako, Sefhako. 2012. "Glass Project to Continue.” Daily News, Friday February 03.

Tian, G. 2010. "The Unique Contribution and the Unique Methodologies: A Concise Overviews of the Applications of Business Anthropology.” International Journal of Business Anthropology 1(2): 70-88.

Tian, G. 2012. "The Rising and Application of Business Anthropology." An Academic Edition of Management 12:39-48.

Tian, G. 2013. "Business Anthropology and Cultural Different Management." Nationalities Research in Qinghai, 24(3):

Tian, G., \& Zhou, D. M. 2012. Business Anthropology. Yinchuan, Ningxia: Ningxia People's Publishing House.

Tian, G., \& Zhou, D. M. 2013. General Business Anthropology, Beijing: China Financial and Economic Publishing House.

Tylor, Edward Burnett. 1871. Primitive Culture, J. Murray. 